\title{
EL AROMA DEL CAFÉ FRANCÉS: APORTES CULTURALES DE LA PRESENCIA FRANCESA EN EL PARTIDO RAMÓN DE LAS YAGUAS, SANTIAGO DE CUBA
}

\section{The aroma of French coffee. Cultural contributions of the French presence in the Ramón de las Yaguas party, Santiago de Cuba}

\section{Claudia López Moreno}

Licenciada en Historia del Arte. Profesora de la Facultad de Humanidades de la Universidad de Oriente, Cuba. ORCID: https:// ORCID.org/0000-0001-7035-5200

Recibido: $13 / 11 / 2018 \bullet$ Aprobado: $2 / 2 / 2019$

Cómo citar: López Moreno, C. (2019). El aroma del café francés: aportes culturales de la presencia francesa en el partido Ramón de las Yaguas, Santiago de Cuba. Ciencia Y Sociedad, 44(1), 73-93. https://doi.org/10.22206/cys.2019.v44i1.pp73-93

\section{Resumen}

Con el desarrollo de la producción cafetalera tras la llegada de los inmigrantes franceses al oriente cubano, a fines del siglo XVIII y principios del XIX, no solo la economía del país se vio beneficiada, sino que también hubo un impacto en lo social y cultural. A pesar de ser un hecho analizado en importantes investigaciones, el modo de vida de esas familias en las haciendas cafetaleras situadas en las zonas montañosas de Santiago de Cuba, no ha sido lo suficientemente estudiado.

El presente artículo es el resultado de la investigación Aportes culturales de la presencia francesa en el partido Ramón de las Yaguas y muestra un acercamiento al panorama cultural desarrollado en este partido a través del modo de vida de las familias francesas allí establecidas. Se tocan aspectos de los comportamientos y las costumbres de los hacendados franceses, así como el progreso en los negocios del café y su reflejo en el estilo de vida, los establecimientos, la moda, la alimentación y las bebidas. Se desarrolla una lectura histórico-cultural, con especial énfasis en las familias más importantes del partido. Los datos aportados básicamente se reflejan en fuentes primarias como testamentos, documentos adscritos y protocolos

\section{Abstract}

With the development of coffee production after the arrival of French immigrants in eastern Cuba in the late eighteenth and early nineteenth centuries, not only the country's economy was benefited, there was also impacted on social and cultural. Despite of being a topic analysed in many investigations, the way of life of these families in the coffee plantations located in the mountainous zones in Santiago de Cuba, has not been sufficiently studied.

This article is the result of the research Cultural contributions of the French presence in the Ramón de las Yaguas jurisdiction, and shows an approach to the cultural panorama developed in this region through the way of life of the French families established. It tackles aspects the behaviors and customs of the French landowners as well as progress in the business of coffee and its influence in the lifestyle, fashion, food and beverages. A historical-cultural approach is developed, with special emphasis on the most important families of the jurisdiction. The data provided are basically exposed in primary sources such as wills, attached documents and notarial protocols of the Provincial Historical Archive of Santiago de Cuba, its complemented with fieldwork contributes to an approach to culture and 
notariales del fondo del Archivo Histórico Provincial de Santiago de Cuba, lo que complementado con el trabajo de campo contribuye a un acercamiento al ideal cultural e identitario de la presencia francesa en ese partido.

Palabras clave: presencia francesa en Cuba; haciendas cafetaleras; memoria cultural; signo francés.

\section{Introducción}

La importancia de un estudio de los aportes franceses en la zona montañosa de Santiago de Cuba es dar a conocer datos significativos de las familias francesas más importantes que se establecieron en el partido Ramón de las Yaguas. Entre estos datos están: el lugar que ocupaban ante la sociedad, el vínculo que reflejaban con la ciudad, las relaciones que mantenían con las demás familias dentro del partido y las acciones que poseían, así como sus formas de vestir, ambientaciones, hábitos alimenticios y festejos. Todo un accionar de prácticas culturales $^{1}$ (Contreras, 2008) que se manifestó como plataforma cotidiana, determinando un modo de vida con referentes de ilustración.

Dentro de los estudios dedicados a la presencia francesa en Santiago de Cuba existen varias investigaciones que constituyen antecedentes fundamentales y de obligada consulta en estos predios. Es importante señalar, en primer lugar, los titulados Francia y Haiti en la cultura cubana y Entre esclavos y libres de Cuba colonial, realizados por Olga Portuondo Zúniga (2014), además del texto Génesis de una ciudad del Caribe: Santiago de Cuba en el umbral de la modernidad, de María Elena Orozco Melgar (2008), los cuales han servido como identity of the French presence in Ramón de las Yaguas jurisdiction.

Keywords: French presence in Cuba; coffee plantations; cultural memory; French sign.

fundamento histórico para resaltar la formación de la nación cubana a partir de la presencia francesa en el territorio oriental de Cuba durante el siglo XIX.

El texto ElSignofrancés en Santiago de Cuba (Morales, 2015) también describe elementos propios de la presencia francesa en la vida cotidiana de la época. Muestra a los hacendados más importantes con propiedades en la ciudad santiaguera, como parte de la dinámica en el comercio exterior, incluyendo a los galos, aunque se limita a ilustrar los acontecimientos desarrollados en los predios urbanos durante el siglo XIX. Sin embargo, sus referencias al progreso económico alcanzado por la producción cafetalera no recrean el modo de vida de los hacendados franceses establecidos en la zona rural como principal exponente de ese desarrollo.

Otras investigaciones vinculadas a la transformación de la imagen rural y la vida en el cafetal francés son expuestas por la arqueóloga Yaumara López en su trabajo Del Paradigma Tecnológico al Paisaje Arqueológico: presencia francesa y cultura del café en el sudeste cubano en la primera mitad del siglo XIX. Santiago de Cuba (López, 2010), así como en Del paisaje natural al paisaje cultural: Concepción de Ti Arriba y la presencia francesa, de Lianet Godínez Mendoza (Godínez, 2013).

1. El término se puede definir como las actividades específicas que realizan las personas dentro de un campo cultural determinado (...), que están orientadas a la formación y/o a la recreación, presupone que son espacios sociales que se van abriendo y consolidando históricamente (procesos de secularización cultural). Concepto determinado por Ricardo Contreras Soto en su publicación Enlace crítico de la cultura. Prácticas culturales.

74 | Ciencia y Sociedad 2019; 44(1): 73-93 • Una mirada desde lo particular 
Figura 1. Plano del partido del Caney, donde se definen los límites del partido Ramón de las Yaguas

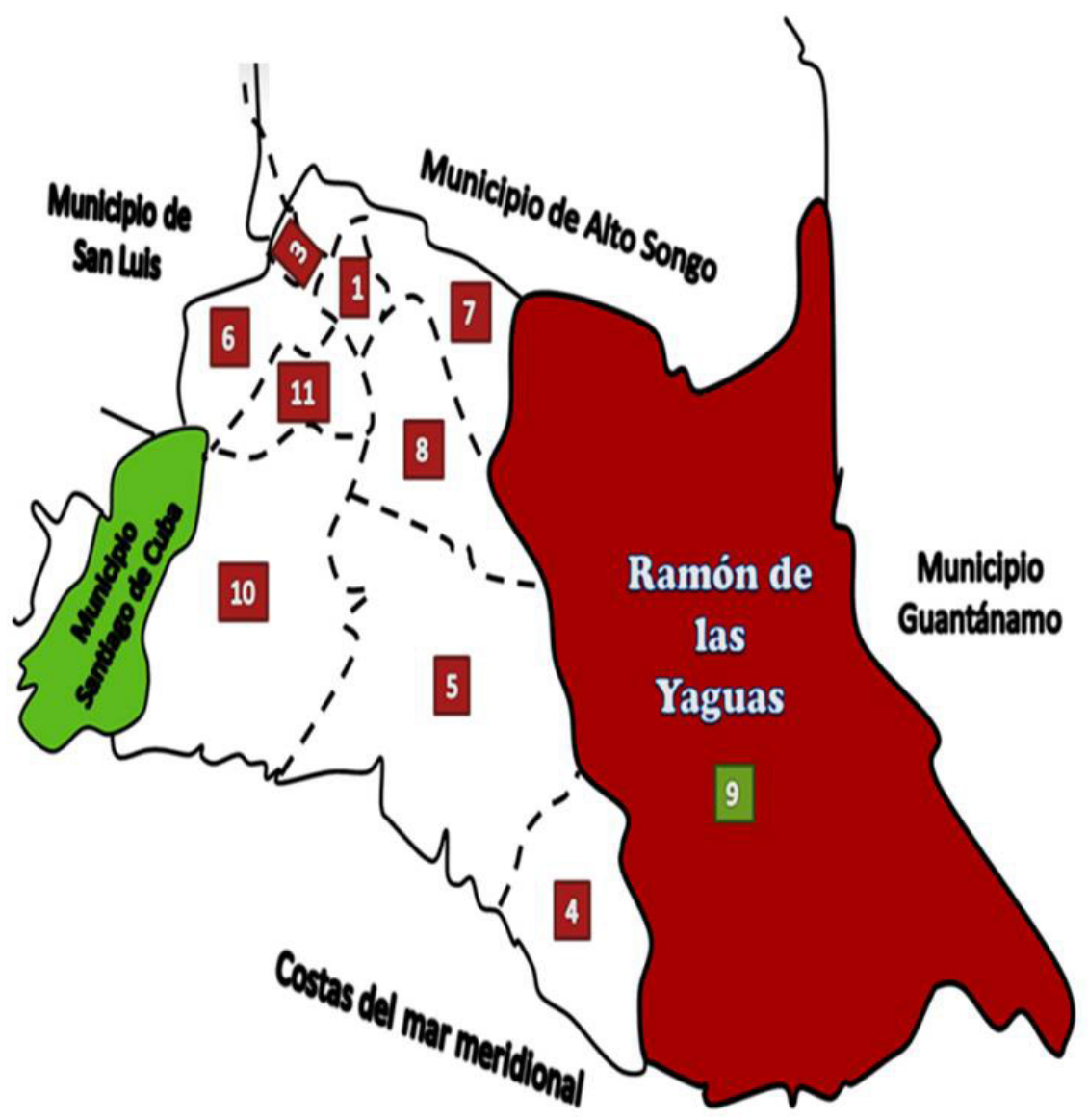

Leyenda:

\begin{tabular}{lll}
\hline$\#$ & Barrios \\
11 & Barajagua \\
2 & Cabecera \\
3 & Cristo \\
4 & Daiquirí \\
5 & Demajayabo \\
6 & Dos Bocas \\
7 & Guaninicú \\
\hline 8 & Los Naranjos \\
\hline 9 & Ramón de las \\
& Yaguas \\
\hline 10 & Sevilla \\
\hline 11 & Zacatecas \\
\hline
\end{tabular}

Fuente: plano original cedido por el cartógrafo de la Oficina del Conservador de la ciudad de Santiago de Cuba Jorge Manet y editado por la autora para resaltar los terrenos del partido.

El presente ensayo, con un enfoquehistórico-cultural, analiza el modo de vida de las familias francesas asentadas en el partido de Ramón de Las Yaguas y el reconocimiento de las haciendas allí localizadas, las cuales hoy son consideradas parte del Patrimonio de la Humanidad por la UNESCO. El período estudiado abarca todo el siglo XIX, tomando como punto de partida el ingreso excesivo de las familias francesas que emigraron desde Saint Domingue a la ciudad de Santiago de Cuba y se insertaron en el negocio del café en el partido Ramón de las Yaguas, hasta el abandono de los cafetales, luego del inicio de las luchas independentistas contra el dominio español a partir de 1868.
Atendiendo a las consideraciones anteriores, se ha planteado como una interrogante básica: ¿Cuáles son los aportes culturales de la presencia francesa en el partido Ramón de las Yaguas dentro del panorama sociocultural cafetalero durante el siglo XIX? Esta interrogante responde al propósito de caracterizar los aportes culturales de la presencia francesa en ese partido y analizar cómo estos se insertan dentro del panorama sociocultural cafetalero del siglo XIx, orientados hacia la transformación de la imagen rural y la implantación de sus modos de vida, costumbres, hábitos alimenticios y formas de vestir. 
Figura 2. Vista de la hacienda cafetalera Fraternidad ubicada en el partido de Ramón de Las Yaguas

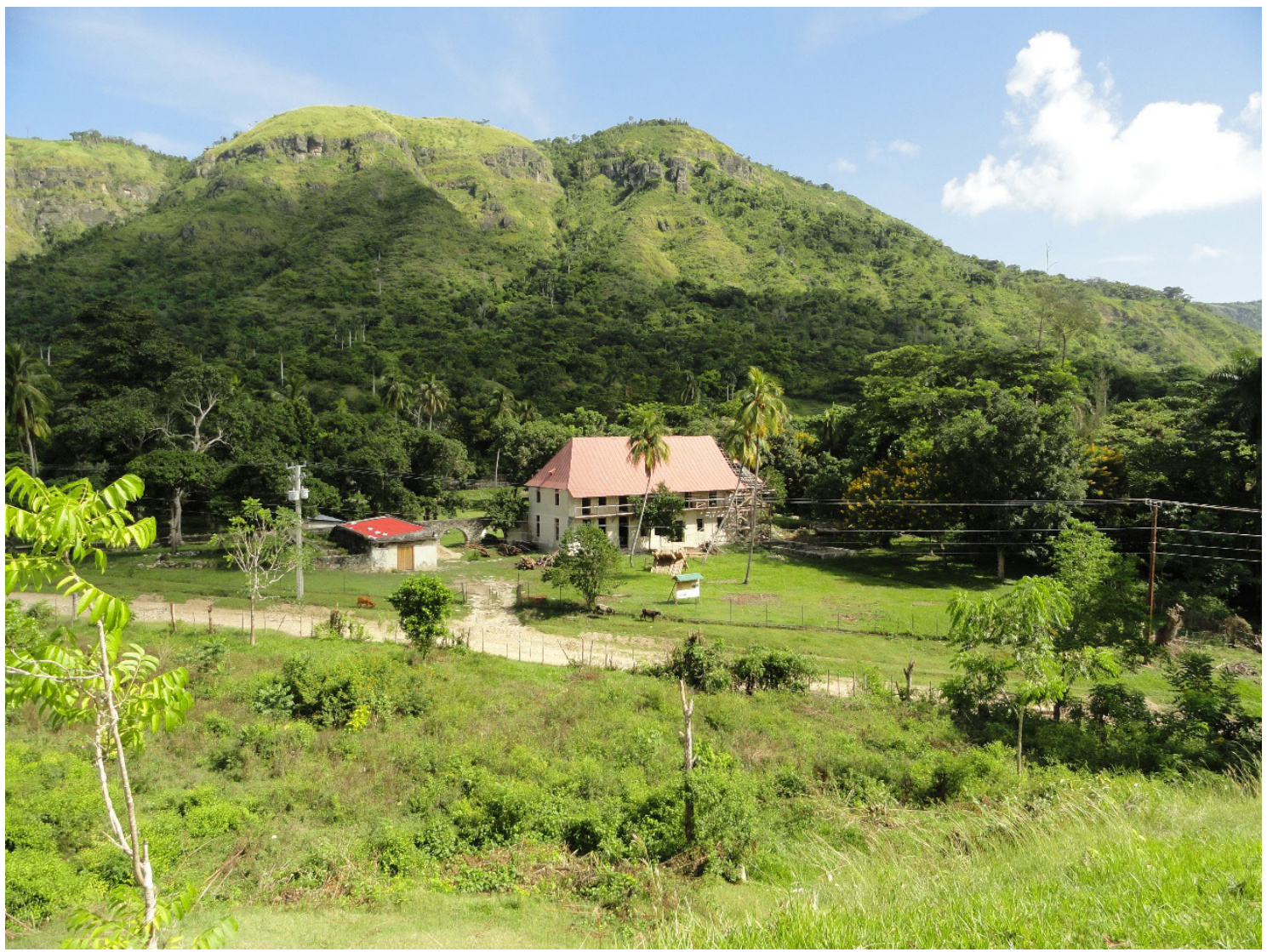

Fuente: imagen cedida por la oficina de Arqueología del Centro de Interpretación y Divulgación del patrimonio cafetalero (Casa Dranguet).

La presencia francesa en el partido Ramón de las Yaguas: El cultivo del café

Los colonos franceses asentados en la parte Oriental de la isla de Cuba y, en especial, en las zonas montañosas de Santiago de Cuba adoptaron formas de vida muy similares a las desarrolladas en Saint Domingue, escogiendo las cordilleras de la Sierra Maestra por motivos climáticos y por una mayor conservación del cafeto² $^{2}$ (Pérez, 1994, p.

2. Según los estudios realizados por la arquitecta Lourdes Rizo en su tesis "La arquitectura cafetalera en Cuba. Siglo XIX" (Rizo, 2003), en las cordilleras montańosas se genera un microclima bastante estable, alcanzándose un promedio anual de temperatura de 26 grados celcius, con máximas en septiembre de 28.3 grados celcius y mínimas de 23.6 en enero. Los vientos predo-
2), además de conservar el quehacer agrario y la explotación esclava. En las plantaciones localizadas en estas zonas se utilizaron las técnicas más exitosas y llegó a perfeccionarse el proceso a partir de las iniciativas puestas en práctica por los hacendados, hasta convertirse en un negocio lucrativo.

Incentivados por el cultivo de café, fundaron partidos a los que nombraron y habitaron. La mayoría de estos fueron apareciendo y evolucionando partiendo de la continua llegada de familias al territorio durante principios y mediados

minantes son alisos, encontrándose además brisas en las montañas y gravitaciones débiles. Condiciones topográficas propicias para el cultivo y desarrollo de cualquier actividad agrícola, tanto por el clima, las precipitaciones y el relieve. 
del siglo XIX, y por el impacto económico logrado por las producciones de café desempeñadas en ellos. Para el año 1807, en el Estado General de las Plantaciones de Café (p. 29), en la Jurisdicción de Cuba, se reflejan los terrenos conocidos como Dos Bocas, La Guira, Guaninicú, Candelaria, Sierra Maestra, Limones, Sacateca, Tiguabos y Sueltos como partidos productores importantes de café. Sin embargo, un año más tarde, para 1808, Ti Arriba, El Cobre, Cambute, la Cordillera de la Gran Piedra y Las Yaguas eran de las tierras que formaban un anillo de decenas de cafetales rodeando Santiago de Cuba (Padrón, 1994, p. 84).

Así, Las Yaguas se convertía en uno de los partidos cafetaleros más significativos de la parte sudeste de la zona oriental del país. Si en sus inicios solo era una pequeña aldea, situada cerca del límite con la ciudad de Guantánamo y compuesta por algunas pobres viviendas, su territorio, luego llegó a comprender todo el terreno de los antiguos partidos de la Amistad, Armonía, Limones, Guaninicúm, Rizo, Barajagua, Ramón y Andalucía. De este modo, cada uno de estos partidos se convirtió en cuartones de Las Yaguas.

El partido se encontraba ocupado por las cordilleras de la Gran Piedra. Limitaba al Norte con el Partido de Jutinicú y el antiguo Mayarí; abajo, por el Oeste, con el Caney; por el Sur, con el mar de la costa meridional; y, por el Este, con la Jurisdicción de Guantánamo (Pezuela, 1866, p. 677). En 1878, según los datos encontrados en los documentos de la época, el partido se renombra a Ramón de las Yaguas $^{3}$. Años más tarde, con las nuevas divisiones territoriales, en enero de 1902, bajo la presencia del Señor Alcalde Municipal Emilio Bacardí y Moreau, según lo estipulado en el orden 23 y 24 de la

3. Este dato fue encontrado en el AHPSC, Anotaduría Hipotecaria, Libro 30, Fincas Rústicas, Casco del cafetal La Caridad en el cuartón de Andalucía, partido Ramón de las Yaguas, de Ruperto Malleta.
Gaceta $^{4}$, se determinó que los terrenos de Ramón de las Yaguas pasaran a ser parte del Caney5.

Aunque las investigaciones realizadas por Jacobo de la Pezuela sobre el partido muestran datos a partir de los años cincuenta del siglo XIX, existen documentos que reflejan la existencia de familias principalmente francesas con sus establecimientos cafetaleros en años anteriores. En el periódico El Redactor, del martes 2 de diciembre de 1845, a esperas del juicio promovido por don Pedro Santiago Causse, se dispuso a anunciar al público la venta de las dos haciendas del cultivo de café nombradas San José y Joven Laura, situadas en el partido de las Yaguas ${ }^{6}$.

(...) 30 caballerías de tierra cada una, 62 esclavos de uno y otro sexo y diversas castas y edades de que se compone la dotación de ambas fincas, sus establecimientos y plantaciones. Estimadas, la primera con toda su esclavitud, en 47170 pesos y 7 centavos, y la segunda sin esclavos, en 22084 pesos 4 centavos, con advertencia de que ambas fincas se enajenan de preferencia reunidas (...). (Parte Judicial, 1845)

Para 1846, la cantidad de café producida en la jurisdicción fue de 383,780 arrobas; sin embargo, los partidos el Ramón, la Amistad (estos dos pertenecientes al partido de las Yaguas) y Cauto eran los que mostraban mayor volumen de producción.

4. El telegrama con la información de la orden de la Gaceta tenía fecha del 28 de enero, pero había sido recibido al día siguiente. Entre los tenientes de Alcalde interino se encontraban en la lectura de dicha orden Francisco Audivert, Federico Rey Bruchet y Nicario Escobar Ramos. Esta información fue encontrada en el AHPSC, Actas Capitulares, libro 3, 1902.

5. Estos datos se corroboran con el plano de las inmediaciones del partido del Caney, levantado a partir del censo de 1943.

6. Este anuncio fue puesto en el periódico desde el 22 de noviembre de 1845. Este periódico fue consultado en el AHPSC, Fondo Juzgado de primera Instancia, materia testamentos, en el legajo 616, expediente 3 del año 1842. 
El precio del café se mantuvo, entre 1838 y 1843 , en 7,00 pesos el quintal, pero descendió entre 1844 y 1846 a 5,00 y 4,00 pesos el quintal (Portuondo, 1996, p. 187) Esto incidía considerablemente en el aumento de cafetales en el partido. Años posteriores, para 1849 , en el mismo periódico en la parte judicial aparece la venta de otras haciendas con la referencia de los siguientes datos:

(...) "Nueva Sofía", a la que está agregada la contigua que se nombra "Santa Rosa", fundadas en 341 carbas de tierra y en el partido de las Llaguas justipreciadas ambas con la correspondiente dotación de esclavos, animales y demás aperos necesarios existentes en la Nueva Sofía, en la cantidad de 141832 pesos, dos reales. (...) Una mitad le pertenece al fallido Don Casamayor y la otra mitad a Don Federico Lescaille (Parte Judicial, $1849)^{7}$.

Las ventas de estas haciendas son una muestra no solo de la presencia de familias en el partido, sino del tiempo que llevaban establecidas. En los archivos de la época aparecen datos sobre la procedencia de los hacendados franceses pertenecientes a este territorio desde ciudades como Orthes, Nante y Rochefort, incluyendo algunos franco domingoises en busca de nuevas oportunidades, españoles y criollos, aunque estos últimos en menor medida. La presencia francesa en el partido predominaba a través de la caficultura. La siguiente tabla únicamente muestra algunos ejemplos:

7. Esta publicación salió el viernes 26 de enero de 1849. Junto al artículo de venta de la hacienda Nueva Sofía del pardo de las Yaguas, aparecían otras concernientes al fallecido Enrique Casamayor. El cafetal "Meca" perteneciente al partido de Bolaño y otra hacienda de fabricar azúcar nombrada "San Felipe" de Guaninicum, en el partido de Dos Bocas. Periódico consultado en el AHPSC, Juzgado de Primera instancia, Materia testamentos, Legajo 652, 1848, exp. 3.
Tabla 1. Muestra de la presencia francesa en el partido Ramón de las Yaguas a través de la caficultura.

\begin{tabular}{lll}
\hline \multicolumn{1}{c}{ Hacendados } & \multicolumn{1}{c}{ Procedencia } & \multicolumn{1}{c}{ Cafetales } \\
\hline D. Clemente Praud & Rochefort (Francia) & María Luisa \\
D. Eusebio Ibonet & Francia & El Triunfo \\
$\begin{array}{l}\text { D. Juan Morales } \\
\text { D. Eugenio de Ri- } \\
\text { beaux }\end{array}$ & Francia & Santa Rosa (Francia) \\
$\begin{array}{l}\text { D. Angel Alberto } \\
\text { Savine }\end{array}$ & Eraternidad, (...) \\
$\begin{array}{l}\text { D. Alfredo R. Bace- } \\
\text { lais }\end{array}$ & Nantes (Francia) & Sidonia \\
$\begin{array}{l}\text { D. Juan Pedro } \\
\text { Ibonet }\end{array}$ & Saint Domingue & Santa Juana \\
$\begin{array}{l}\text { D. Pedro Leolis- } \\
\text { Labal }\end{array}$ & Jeremias (S. & Dos Hermanos La \\
D. Juan B. Duverget & Jeremias (S. & Cafetal al sur de los \\
& Domingue) & terrenos de Santa \\
& & Juana \\
$\begin{array}{l}\text { D. Federico Lescaille } \\
\text { D. José Maroto }\end{array}$ & Saint Domingue & Nueva Sofía \\
$\begin{array}{l}\text { D. Juan de Mena } \\
\text { Garibaldo }\end{array}$ & La Habana. Cuba & La Unión \\
D. Ignacio Carbonel & Cataluña. España & Felicidad \\
\hline
\end{tabular}

Fuente: datos recopilados por la autora en las testamentarias de la época.

Además de los 106 cafetales distribuidos en este partido, contaba con 3 ingenios de poca producción, 13 haciendas de cría y labor, más unas cuantas vegas de tabaco y algunos cacaotales que en 1857 produjeron cerca de 11,000 arrobas de cacao (Pezuela, 1866, p. 678).

Con el establecimiento de familias en el partido, para 1858 el estado de población y riqueza agrícola e industrial determinaba la presencia de 47 hacendados blancos y un solo administrador de finca de la misma tez. Su población aumentó en 1862 disponiendo de 807 individuos blancos; 1,704 libres de color y 3,310 esclavos, o sea, un total de 5,793 personas. En el mismo año había 935 casas, de las cuales 87 eran de mampostería, 249 de tabla y teja, 36 de yagua y las restantes de embarrado (Pezuela, p. 678). 
Para ese mismo año el partido Ramón de las Yaguas se encontraba produciendo 110,646 arrobas de café y 10,840 de cacao. La elevada producción del partido no solo continuaba destinando una vida ilustre para los hacendados caficultores, sino que se convertía en un aporte financiero para la ciudad.

En Santiago de Cuba se contaba con 437 cafetales, 3,332.229 arrobas y 1,245,859 en valor del café. Un año más tarde quedaban solo 782 cafetales, con una producción de 185,385.50 quintales: el Caney con 15, el Cobre con 96, Jutinicú con 55, La Enramada con 21, Palma Soriano con 45 y Las Yaguas con 74, convirtiéndose en el segundo partido con mayor producción cafetalera $\mathrm{y}$, por tanto, uno de los que tenía mayor número de familias francesas establecidas (Pérez, 1944, p.81). Sin embargo, en 1866 Ramón de las Yaguas, según Jacobo de la Pezuela, contaba con 106 cafetales y se establecía así como el principal y mayor productor.

\section{Las familias francesas: un ejemplo de opulencia vinculada al café}

La comunidad francesa que se estableció en el partido Ramón de las Yaguas desarrolló y fundó espacios de confort a disposición de la caficultura ${ }^{8}$. Los ingresos financieros adquiridos por la producción cafetalera se convirtieron en el principal detonante de un nivel de vida que permite diferenciar a las familias allí establecidas, ya sea por el número de bienes que poseían o por el reconocimiento de sus dueños en los negocios del café. No obstante, mantuvieron entre sí fuertes vínculos sociables como estrategia para proteger sus posesiones y fortalecer su cultura y su identidad.

Las familias establecidas en el partido disponían de grandes establecimientos para la producción.

8. A diferencia de otros partidos, Ramón de las Yaguas solo contaba con tres ingenios y sus dueńos no eran precisamente galos, predominan los cafetales y puede decirse que un 90\% de los dueños de estos eran franceses.
La prosperidad del lugar fue facilitada, en gran medida, porque los hacendados franceses ya tenían conocimientos de que el negocio del café era lucrativo y llegaban dispuestos a invertir en dichas tierras. De ahí, el hecho de que la mayoría procediera de Francia y Saint Domingue.

Buena parte de la sociedad francesa poseía establecimientos cafetaleros en otros partidos, incluyendo, en menor medida, los pertenecientes a la jurisdicción de Guantánamo. La posesión de más de un bien económico le concedía autoridad e influencia al hacendado francés que representaba a su familia ante el resto. Muy pocas eran las familias que vivían de manera precaria. Los hacendados más exitosos administraban varias haciendas a la vez, fuesen de franceses, españoles, criollos of franco domingoises. Se convertían en representantes de los cafetales que dirigían, se encargaban de los asuntos económicos directamente y de los términos legales en determinadas circunstancias; desde la compra de los alimentos, las ropas y los utensilios del hogar, hasta lo correspondiente al negocio del café: maquinarias, ventas y embarcaciones del fruto.

Vivir en el campo no fue un acontecimiento que desmeritara el prestigio de estas familias; al contrario, eran reconocidas por sus ingresos económicos en la dinámica del comercio interior y exterior a través de la caficultura. De igual modo, gran parte de ellas conservaban sus viviendas o almacenes en la ciudad; hecho que les permitía establecer una relación directa con los nuevos acontecimientos culturales de la sociedad francesa ilustrada del momento. Este vínculo ciudad-campo fortalecía las acciones financieras del hacendado francés al mismo tiempo que posibilitaba que las familias en la zona rural se actualizaran sobre las eventualidades cotidianas desarrolladas en la urbe.

Un ejemplo de esto es la figura de don Santiago Eugene de Ribeaux ${ }^{9}$, quien comienza a resaltar ante

9. En los documentos de la época aparece escrito este apellido 
los referentes de la alta sociedad francesa establecida en el campo y que mantenía, de igual modo, establecimientos en la ciudad dedicados al comercio al por mayor. Comerciante, agente prestamista y administrador de haciendas cafetaleras, cónsul de Francia en Santiago de Cuba y diestro para los negocios. Fue uno de los hacendados franceses dedicados a dinamizar el comercio en la ciudad y a exportar cargamentos de café hacia ciudades como Nueva Orleans y Burdeos.

La familia Ribeaux ${ }^{10}$ fue una de las más reconocidas. Santiago Eugene de Ribeaux, junto a su consorte dońa Juana Luisa Girard ${ }^{11}$, tuvo cinco hijos, tres de ellos varones y dos hembras: don Santiago Eduardo, don Anastor Alfonso, don Domingo Gustavo, dońa Luisa Carolina ${ }^{12}$ y doña María Josefa Matilde, esta última la más pequeña. Crecieron en un ambiente próspero, apadrinados por la riqueza de sus padres y el cariño de sus abuelos maternos, quienes a cada uno de sus nietos le legaron como símbolo de su amor y bondad una pequeña dote ${ }^{13}$. Como gran parte de las familias más adineras, preocupados

con v o b (Riveaux o Ribeaux), haciendo referencia a la misma familia y para evitar confusiones la autora ha decidido utilizar Ribeaux.

10. Nacido en Orthes, Francia, en 1799. Sus padres eran don Juan Bautista de Ribeaux y dońa Juana F. de Raure. APSC, Protocolos Notariales, Testamentos.

11. Hija del hacendado don Agustín Girard y doña Barbara Rey, los dueños del cafetal Monte Bello.

12. Contrajo matrimonio con don Juan Diego López de Quintana, con quien tuvo un hijo, don Juan L. Diego López Quintana y Ribeaux. APSC, Protocolos Notariales, Testamentos, documento cedido por la licenciada en Historia del Arte Lianet Godínez.

13. Le legaron a don Santiago Eduardo Ribeaux 200 pesos, a Gustavo y a don Alfonso Ribeaux 100 pesos a cada uno. A dońa María Luisa Carolina Ribeaux 300 pesos por indemnización de una negra que su abuelo le había regalado en su niñez. A don Santiago Eduardo Ribeaux como mayor de sus nietos varones le legó el reloj que fue de su abuelo, queriendo que se le reemplace con otra la cadena de oro. APSC, Juzgado de Primera Instancia, Testamentos, leg. 645, exp. 6,1847. por la educación de sus hijos, a partir de 1843 los enviaron anualmente a estudiar a Francia.

Eugene Ribeaux y su familia contaban como parte de sus ingresos financieros con seis acciones de la Compañía Delbasen, la ciudad santiaguera y catorce acciones más del ferrocarril de Guantánamo. Al mismo tiempo, mantenían negocios con la compañía del comercio de Burdeos, a la que prestaba muy buenos servicios ${ }^{14}$. En el campo poseían más de diez cafetales, cuatro de ellos pertenecientes al partido Ramón de las Yaguas: Fraternidad, Santa Paulina ${ }^{15}$, La Emilia y Nueva Cecilia. El resto de las haciendas ${ }^{16}$ se encontraban en otros partidos como el de la Amistad, Candelaria y Yateras, este último perteneciente a los terrenos de Guantánamo.

En el caso de hacienda La Fraternidad (ver figura 2), como ejemplo que ha perdurado luego de dos siglos, cuenta con una casa de vivienda y almacén de dos plantas con balcón. La planta baja dispone en sus espacios de cinco cuartos en una parte y la otra con dos cuartos más, una cocina, un comedor y una sala grande. Mientras, la planta alta contaba con seis cuartos y un salón corrido con buena amplitud. Un tercer nivel o barbacoa que servía

14. En 1843 Ribeaux queda endeudado ante la compañía del comercio de Burdeos por una suma de 40,000 pesos, viéndose obligado a hipotecar la mitad de las haciendas de café Fraternidad y Candelaria como seguridad de pago, en caso de no cumplir en un plazo de uno a tres ańos, a partir de la fecha de la indicada escritura. APSC, Anotaduría Hipotecaria, fincas rústicas, libro 36. 1843, p. 173.

15. Para 1843 la hacienda le pertenecía todavía a don Francisco Payson. Ya para 1870 se tiene referencia de que se había anexado a la hacienda Fraternidad Eugene de Ribeaux. APSC, Anotaduría Hipotecaria, fincas rusticas, libro 36, 1843 y libro 30, 1870.

16. El resto de las haciendas: Santa Elena, con ocho caballerías y veinte y ocho cordeles en el cuartón de la Demajagua, partido Jutinicú. Monte de Oro, La Carolina, San Ípolito y la mitad del casco del cafetal Valparaíso, situado en el cuartón de los Hondones, partido de Montelibano en la jurisdicción de Guantánamo; correspondiendo la otra mitad a los Señores Brooks y Compañía. APSC, Anotaduría Hipotecaria, fincas rústicas, libros 30, 31 y $35,18231870$. 
para almacenar café y cacao; se supone que bajaban el café a la planta baja a través de un embudo de tablas. Solo la mitad de la vivienda era habitacional, la otra parte se encontraba en disposición de la producción de café. Disponía de siete secaderos, seis tanques para secar y barracones para 120 esclavos $^{17}$. El agua proveniente del batardó llegaba a través de arcos de medio punto que funcionaban como acueducto, distribuyéndola hacia la zona de producción y la doméstica.

Sus haciendas cafetaleras eran fuertes productoras y le permitían a Ribeaux la comercialización de importantes cargamentos de café hacia ciudades europeas. En febrero de 1842 salía con destino a Burdeos el bergantín francés Matilde, con una carga de 339,525 libras de café pertenecientes a este hacendado (Redactor, 1842) ${ }^{18}$. Estas operaciones comerciales iban dotando a la familia de grandes ingresos y prestigio en los negocios del café.

\section{Familias francesas y vida cultural en el partido Ramón de las Yaguas}

La forma de vida en el partido para las familias francesas reflejaba prácticas y costumbres análogas a las desempeñadas en la ciudad por los propios galos: los hábitos alimenticios, la moda, la ornamentación de las moradas, las vajillas lujosas, la educación a la francesa y el estilo ilustrado. El detalle diferenciador con respecto a las establecidas en la ciudad estuvo determinado además de sus construcciones por los comportamientos y modos de actuación que

\footnotetext{
17. Información obtenida de la familia Brugal. Estos fueron los últimos dueños de la hacienda antes que pasara a ser patrimonio de la UNESCO. Otros datos fueron observados en el trabajo de campo de la autora.

18. Este dato fue obtenido de la "Parte Mercantil" del periódico, fechado con el 21 de febrero de 1842. Para más información ver la tesis de diploma de Milenis Romero: Apuntes para la historia de las haciendas cafetaleras en la zona oeste de la jurisdicción de Santiago de Cuba entre (1840-1868), p. 45.
}

respondían a tipologías propias de la zona rural y por las circunstancias que condicionaban la cultura del café.

Las familias más apoderadas del partido se encargaban de reflejar en sus haciendas y modos de desarrollarse el peculio y la buena vida de que disponían, marcando un sello que las diferenciaba de las propias familias galas, las españolas y las criollas. Vivir a la francesa fue un factor que, al igual que en la ciudad, fue determinante para el desarrollo en la mentalidad de la sociedad criolla. Se convirtió en un patrón a seguir por ser lo nuevo y trascendental mundialmente.

Los comportamientos y las acciones cotidianas desarrolladas en el cafetal quedaban regidos fundamentalmente por la cosecha y las actividades que de ella se derivaban.

(...) para la familia del hacendado existían ocupaciones relacionadas con menesteres del cuidado del hogar, la educación de los hijos, el desarrollo de una vida cultural y la socialización, cuestiones que demandaban un tiempo considerable y condicionó la jerarquía de los espacios dedicados a ello (...). (López, 2010, p. 117)

Según las especificidades en la investigación de la arqueóloga Yaumara López, la casa señorial de un solo nivel se dedicó sobre todo a las funciones domésticas esenciales: habitaciones, sala de estar, biblioteca. Sin embargo, cuando la casa señorial era de dos pisos, se encontró que en los cafetales pequeños y medianos la planta baja podía servir de almacén de café y útiles, mientras una escalera interior o exterior conducía al piso superior o principal donde existían las dependencias domésticas. Estas características habitacionales no se manifestaron de igual modo en las casas francesas de la zona urbana:

La organización planimetría de la vivienda se estructuró a partir de los siguientes espacios: sala, 
Figura 3. Imagen que muestra parte del estilo de vida francés

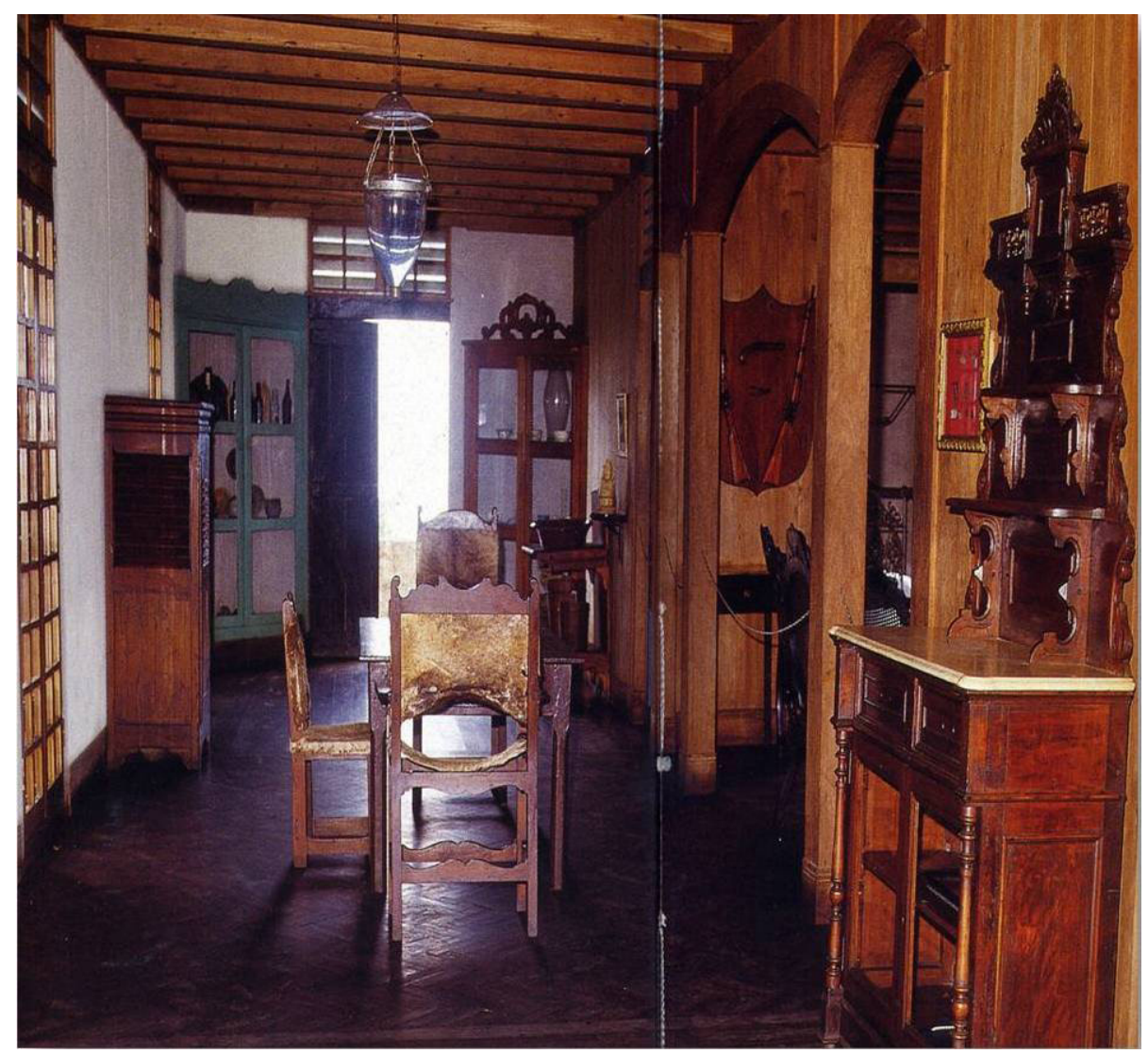

Fuente: extraída del texto "El Oriente Cubano y los factores de cambio: el aliento francés", de la Dra. C. María Elena Orozco Melgar.

saleta (antesala), comedor, aposentos, zaguán, cocina, lugar reservado al aseo y patio (...) En aquellos dedicados a la sociabilidad, los más cercanos a la calle, se encontraban la sala, la saleta y el comedor (...), mientras pertenecía al privado, la alcoba, el cuarto de estar, el cuarto de tocador, el retrete y el excusado (Morales, 2015, p. 61).

En las mansiones de los franceses establecidos en la ciudad la distribución de los espacios crecía en cuanto a privacidad; mientras en las haciendas cafetaleras se compartía en un mismo ámbito varias actividades -de ahí que los aposentos también funcionaran como lugar de aseo y tocador-. Por otro lado, la disponibilidad en terrenos que proporcionaba la vida en el campo permitía que espacios como la cocina, integrados dentro de la morada en la zona citadina, se encontraran alejados de las haciendas en el campo. El cambio nunca estuvo en los hábitos y comportamientos de las familias galas establecidas en ambas zonas, solo en la distribución y disposición de los recintos en que se desarrollaban.

La parte habitacional de las haciendas según los datos encontrados en los documentos de la época revelan espacios como las habitaciones, la sala de estar, la biblioteca y el comedor. La mayoría de los objetos que ambientaban la morada eran de lujo y buen gusto, gran parte de ellos traídos desde Francia, otros confeccionados por ebanistas franceses que mantenían la calidad del estilo. El mobiliario de estos espacios fue trabajado con madera de cedro y caoba; en algunos casos, sobre todo cuando se 
trataba de muebles criollos la madera era pintada ${ }^{19}$; circunstancias evidentes en haciendas de franco domingoises y criollos.

Por otro lado, la ventilación fue uno de los factores que influyó directamente en la disposición de los espacios de confort. El número de puertas y ventanales eran proporcionales a que más allá de buscar privacidad estuvieran a disposición del clima tropical y así poder disfrutar de los privilegios de la naturaleza campestre que le rodeaba. Las finas cortinas que cubrían las ventanas de las haciendas $y$, en especial, las ubicadas en las habitaciones funcionaban como elemento decorativo, al mismo tiempo que evitaban la incidencia de la luz solar, sin estorbar el fresco de las brisas.

Las habitaciones o los aposentos funcionaban como lugar de descanso, embellecimiento e higiene personal. Disponían de tocadores con sus espejos que permitían el acabado de sus peinados y cajones para guardar instrumentos de belleza como los perfumes y adornos. Las cómodas, los armarios y los baúles, de igual manera, estaban presentes para guardar las prendas de vestir y otros artículos personales.

Las camas de cedro y bronce con columnas o pilares eran vestidas con sábanas de coleta y finas fundas de algodón, acompañadas por mesitas de noche que sostenían candelabros de vidrio o cobre con guardabrisas. En haciendas donde habitaban niños estaban presentes las cunas de madera en conjunto con sus espejos. Por otro lado, el uso del mosquitero en las camas y catres fue esencial para evitar las picaduras de mosquito $\mathrm{u}$ otros insectos ${ }^{20}$.

19. Los domingueños Ivonet contaban con siete sillas criollas, mientras el natural don Juan Mena Garibaldi disponía de dos balances de madera pintada con rejilla. Datos encontrados en su testamentaria.

20. Artículos de habitación presentes en la testamentaria de don Santiago Randich, dueño del cafetal Plasencia y de don Savine (ambos provenientes de Francia).
Al funcionar las habitaciones también como espacio o lugar de aseo, estuvieron presentes utensilios para la higiene como los pediluvios de hojalata para lavar los pies, las bañaderas redondas y los vasos o jarros de este mismo material ${ }^{21}$. Estos objetos permanecían en mesitas esquineras dentro de la propia habitación, en conjunto con otros instrumentos de lavado. Para los hábitos de limpieza utilizaban jabones americanos de marca Colgate o de olor (podrían ser de color amarillo o blanco); la mayoría de las haciendas se encontraba abastecida de este artículo por cajones o docenas ${ }^{22}$.

La presencia de cuadros en las habitaciones era frecuente, principalmente prevalecía la figura de santos. Las representaciones de San José y la Virgen de la Caridad en grandes dimensiones se mostraban en aposentos como los de la familia Maroto. De igual manera, se colocaban piezas pictóricas de menores formatos o colgaban sus sables como evidencia de que pertenecieron a la infantería o el ejército de su país.

La sala de estar representaba recibimiento y sociabilidad. Posibilitaba el intercambio familiar y las tertulias con visitas provenientes del propio partido o llegadas de la ciudad. Se encontraba amueblada con alrededor de seis taburetes de cuero, cedro o caoba (algunos con pajillas), dos sillones y dos balancines de los mismos tipos de madera, además de una mesa central y dos mesitas esquineras. Las mesas de correderas aparecían como elemento utilitario y exhibición de sus vajillas de porcelana; mostraban las tasas de té o café con sus cafeteras o teteras.

21. Testamentaria de don Alberto Savine, dueño del cafetal Santa María.

22. En las testamentarias de don Carlos Debrosse, dueño del cafetal Armonía, en el partido Ramón de las Yaguas, permanecían cajas de jabones Colgate, así como docenas de jabones amarillos y blancos. 


\section{Figura 4. Cuchillo de plata de mantequilla encontrado en la hacienda cafetalera Fraternidad}

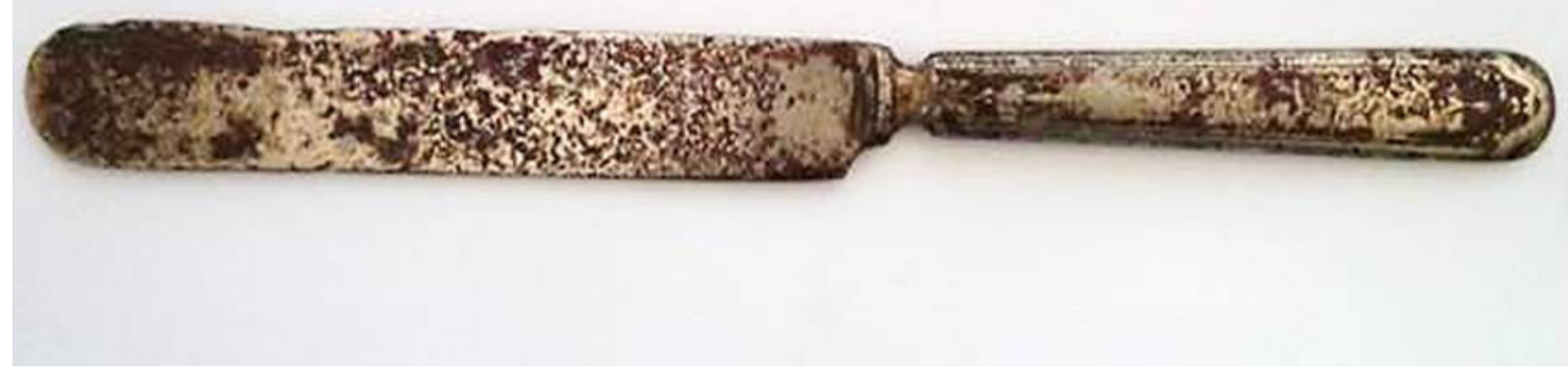

Fuente: imagen cedida por la oficina de Arqueología del Centro de Interpretación y Divulgación del patrimonio cafetalero, Casa Dranguet.

El escaño ${ }^{23}$ de cedro fue un mueble poco común en las haciendas del partido Ramón de las Yaguas, por lo menos así lo revelaron los documentos de la época. Este fue un asiento que estuvo de boga hasta mediados del siglo XIX, cuando aparecieron los sofás de estilo Imperio. Sin embargo, la familia franco domingoises ${ }^{24}$ de don José Maroto conservaba este tipo de mueble. Puede que haya sido un sofá ubicado en la sala de estar o en el espacio dedicado a la biblioteca. Por otra parte, las paredes que delimitaban dicho espacio revelaban variedades de cuadros de mediana o pequeño formato, espejos de luna con los marcos de caoba y relojes de péndulas.

Los juegos de mesa no faltaron como alternativa para los momentos de ocio. El ajedrez fue uno de los más disfrutados, sobre todo en esa época donde se abogaba para que se convirtiera en un deporte

23. Asiento largo con respaldo donde pueden sentarse tres o más personas. No es tan bajo como el sofá, sino como una silla larga y de misma altura.

24. Este término se utiliza en este trabajo para designar a las familias de ascendencia francesa que habían llegado al oriente cubano procedente de Saint Domingue o Santo Domingo Francés. más ${ }^{25}$. Estos espacios de recreación y relajamiento se desarrollaron alejados de los horarios de trabajo o negocios, permitiendo el intercambio con la familia o los invitados.

El arte de la lectura y la excelencia en el conocimiento fueron características relevantes que identificaron al francés ilustrado. Así, las bibliotecas trabajadas en madera de caoba ocuparon un lugar importante en las haciendas. En el partido Ramón de la Yaguas hacendados franceses como don José Alberto Dufourg llegaron a tener más de setenta y tres libros con variedad de temáticas. Este espacio permitía además hacer gala de artículos corrientes convertidos en lujo, como lapiceros fundidos en oro o plata ${ }^{26}$. De igual modo, los potes de tinta y el ilustre papel florete ${ }^{27}$ no faltaron en este espacio.

Conservaban volúmenes de las obras más importantes de Europa, así como libros educativos que les permitían mantener el correcto aprendizaje

25. Teniendo en cuenta que aunque se jugaba el ajedrez que conocemos hoy desde siglos anteriores al XIX, el primer campeonato oficial del mundo de ajedrez se organizó en 1886.

26. Artículo del hacendado don José Dufourg.

27. Encontrado en la testamentaria de don José Maroto. 
de sus hijos, como los tomos de gramática, análisis lógico, historia moderna e incluso manuales de usos y costumbres ${ }^{28}$. No obstante, era recurrente encontrar en estos libreros varios tomos de diccionarios de francés y español, posibilitando el diálogo entre los hacendados galos y criollos o para los naturales que disponían de los servicios de mayorales franceses. Asimismo, los diccionarios de Casa Rústica y Diarios de Comisiones útiles no faltaron, al igual que los libros de medicina.

Los hábitos ilustrados de las familias francesas permanecían en la vida cotidiana desarrollada en los cafetales del partido y el hacendado criollo, por su parte, se exteriorizaba de acuerdo a estos mismos referentes. Un recinto importante dentro de la hacienda fue el comedor, que conservaba la visión galante y cortesana de la época, resaltando su peculio ante el resto de los espacios domésticos. Las alhajas y vajillas finas puestas en exhibición jerarquizaban a sus dueños presumiendo del nivel económico que poseían. El espacio, además de su papel esencial de reunir a la familia en el importante momento de efectuar cada comida, fue propicio para agasajar a los huéspedes e invitados (López, 2010, p.120).

Familias como la del francés Alberto Savine disponían de juegos de comedor de caoba, cubriendo las mesas con finos manteles, servilletas o paños para las manos. Los escaparates, las vidrieras y los mostradores revelaban platos, tasas, fuentes, ensaladeras y soperas de porcelana de loza blanca y perlada ${ }^{29}$, además de

28. Estos libros fueron encontrados en la hacienda Sidonia para la educación del niño Antonio Florencio Miguel Bacelais, hijo legítimo de don Miguel Enrique R. Bacelais con una esclava de don Riverí, quien había sido expulsado de la Real Sociedad Patriótica por no estar a la altura de una escuela como esta. Para más información consultar el intestado de don Miguel Enrique Ruche Bacelais.

29. En la hacienda Fraternidad se encontraron objetos de porcelana de finas marcas como: Plato W. \&. T. Adams Turstall Imperial Porcelain"; Loza blanca; Plato; Societe Ceramique Maestricht; Holanda; Loza perla; ambos ejemplares pertenecientes al finas copas para brindar; mientras que en las gavetas se guardaban las reservas de los demás utensilios como la cubertería. Las mesas esquineras también servían para mostrar y guardar las lozas. No faltaban los tinajeros ${ }^{30}$ con sus tinajas, aunque en algunos casos aparecían recipientes como la damajuana ${ }^{31}$, garrafa de loza y vidrio, fundamentalmente con forma esférica (ver figura 5).

La plata fue el metal más común en los cubiertos (ver figura 4), en tanto cucharas, tenedores y cuchillos, incluso las pequeñas cucharitas para la salsa y el café. En el comedor de la hacienda del criollo don Juan Mena Garibaldi disponían incluso de cafeteras y cucharones del mismo metal ${ }^{32}$, en caso de este último con el cabo de madera. Algunas familias preferían cubiertos con marcas o sellos que las identificaran, en otros casos los cabos mostraban figuras que los distinguía del resto de los cubiertos, como los tenedores con cabo de $\operatorname{tarro}^{33}$. En las comidas donde la carne era el plato principal los trinchantes y cuchillos se convertían en utensilios fundamentales como sujetadores o separadores y para cortar.

Aunque con menos frecuencia, otros metales estuvieron presentes en la variedad de la confección

siglo XIX y, por ende, a la familia allí establecida. Información obtenida por la arqueóloga Denia Ladrón de Guevara Pérez, perteneciente a la Oficina de Arqueología del Conservador de la ciudad de Santiago de Cuba.

30. En algunos testamentos como el de don Juan Mena de Garibaldi hacen referencia al tinajero como mueble para guardar loza, de cedro con luces y columnas negras.

31. Restos de damajuana fueron encontradas en las cercanías del cafetal Fraternidad por los arqueólogos de la Oficina del Conservador de la ciudad de Santiago de Cuba, según lo afirma la arqueóloga Denia Ladrón de Guevara Pérez como parte del equipo.

32. 17 cucharas y 12 tenedores de plata que pesaban 39 onzas cada uno y 11 cucharitas de café que pesaban 11 onzas y media cada una. Testamentaria de don Juan Mena Garibaldi y su esposa doña Higimia Anaya.

33. Cubiertos encontrados en la hacienda de don Ángel Alberto Savine. 
Figura 5. Fragmentos de Damajuana
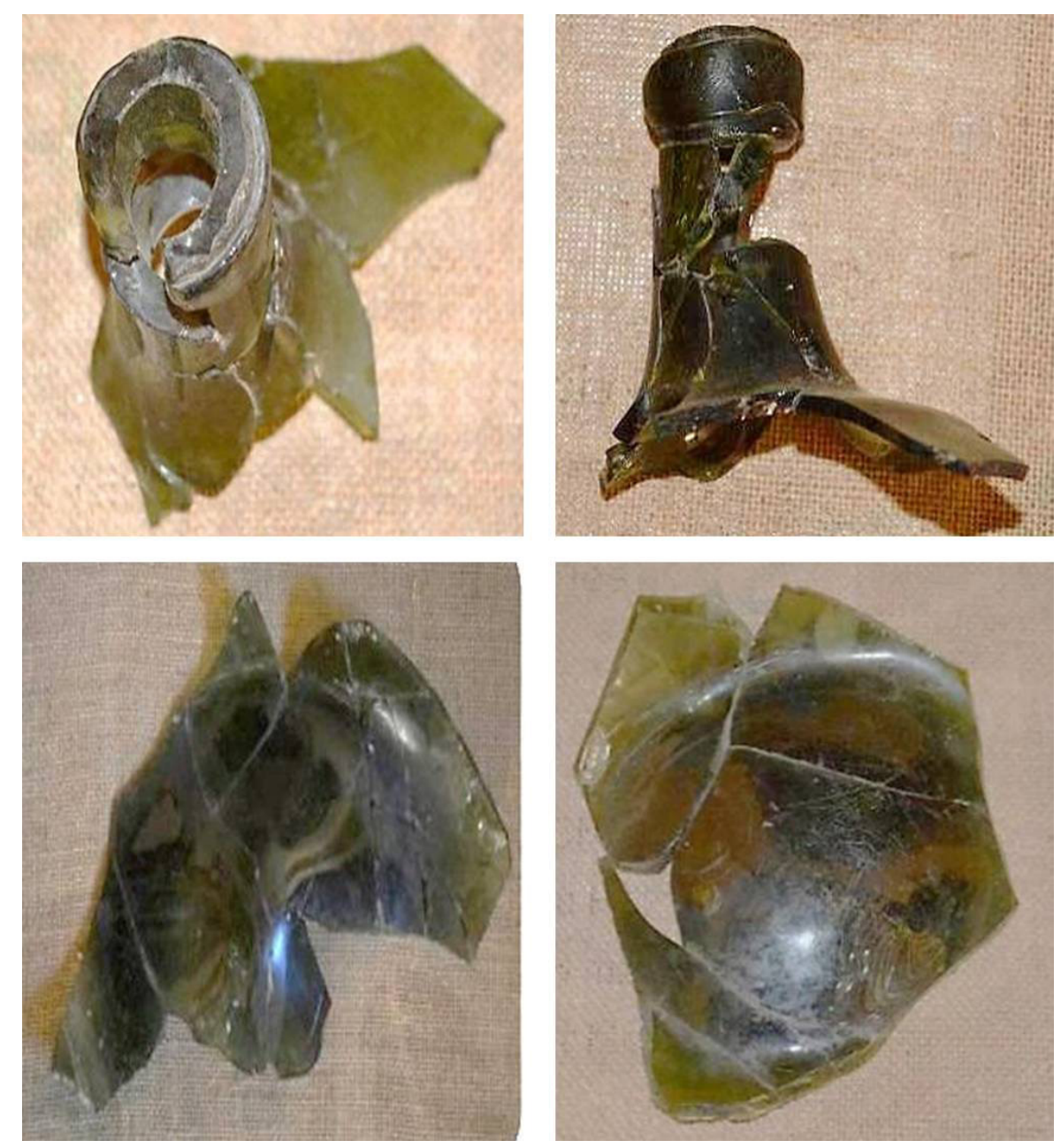

Fuente: imagen cedida por la Oficina de Arqueología del Centro de Interpretación y Divulgación del patrimonio cafetalero, Casa Dranguet.

del conjunto de utensilios para el quehacer del ritual cotidiano de tomar los alimentos. Algunas familias francesas, como los Savine, utilizaban las cafeteras de cobre, mientras franco domingoises, como los Maroto, preferían el estaño en jarros y azucareras. Por otro lado, la familia Ribeaux, para simular el color y brillo de la plata, compraba sus cubiertos de alpaca, también conocida como plata alemana o metal blanco (muy semejante a la plata real).

Algunas familias franco domingoises no disponían de grandes cantidades de alhajas en comparación con las francesas, que las tenían por docenas. En algunos testamentos se hace referencia a cucharas y tenedores de hierro o simplemente a cubiertos comunes. Estos casos estuvieron presentes en familias como los Ivonet.

En contraste, la cocina era un espacio fundamental en la vida del batey y, aun cuando eran estructuras sin mayor complejidad constructiva, se dotaron de gruesos muros de mampostería y guardaban en su interior una plataforma con varios anafres para la cocción de los alimentos con el empleo de leña o carbón.

El comedor era el espacio para ostentar, mientras la cocina era el lugar para elaborar. Hornillas, 
calderos, sartenes, ollas esmaltadas, espumaderas, mesas de trillar, molinos de maíz u otros utensilios para la elaboración de los alimentos se encontraban fuera del recinto señorial, así los olores de la comida preelaborada y el humo del carbón no irrumpían en los ambientes refinados de los dueńos del cafetal. De esta manera, los esclavos solo permanecían en las haciendas para realizar los servicios domésticos y para la preparación de la mesa en los horarios de las comidas.

\section{Hábitos alimenticios, bebidas y moda}

La mesa servida cada día entregó un arte culinario diferente que sumó a la experiencia francesa las costumbres alimentarias locales que fueron aprovechadas y asumidas, e incluso la de la dotación esclava de la hacienda (López, 2010, p. 120) Los hábitos alimenticios de la gran comunidad francesa establecida en el partido estuvo presente, aun y cuando no existe referencia de la presencia de cocineros franceses a disposición de las familias, como sucedía con frecuencia en la ciudad. Esto disponía de la precisión de los dueños galos en la supervisión de la elaboración de los alimentos. Sin embargo, teniendo en cuenta que los platos eran confeccionados y preparados por servidumbre criolla $a^{34}$, puede suponerse que la presencia de las costumbres de estos se hizo evidente a largo plazo.

Se cocinaba con carbón en manteca de cerdo extraída de las mismas crianzas. El vinagre, las cebollas y las pimientas no faltaban para darle el acabado a lo cocido, mientras que el vino seco refinaba el aroma de las carnes. Por otro lado, la manteca o el aceite de coco envasado en frascos y botellas se usaba sobre todo para enriquecer algunas salsas y para la elaboración de la pastelería. El

34. La familia Praud disponía del servicio de más de 15 esclavos criollos distribuidos: los hombres para el arado y trabajo de la tierra y las mujeres en los servicios domésticos de la hacienda, entre ellas la criolla Luisa de 32 años encargada de la cocina. nombrado pan francés no faltaba en las haciendas, podía acompañarse con queso o huevos traídos de los gallineros de la propia hacienda. Las galletas de leche y la mantequilla fueron otra opción dentro de la variedad de picados a disposición de la alimentación a primera hora del día. La leche fresca y el chocolate ${ }^{35}$ permitían digerir la delicadeza de los platillos servidos ${ }^{36}$.

Según la investigación del historiador Ismael Sarmiento, Alimentación y relaciones sociales en la Cuba Colonial, para cocinar se tenía mayor predilección por la manteca de cerdo que por el aceite de oliva, que se emplea más en las ensaladas. Mientras, “(...) los quesos y las mantequillas que se consumen en los campos son preferentemente de fabricación casera (...) esta última por la ausencia de refrigeración, de elaboración y consumo rápido (...) (Sarmientos, 2003, p. 206)".

Los dulces también formaban parte de la alimentación; podían ser comunes en el desayuno, como complemento placentero; servidos como postres, luego de las comidas; y a medias tardes, en el horario de la merienda. La disposición en los almacenes de las haciendas de productos como la harina permitía la elaboración de pequeños pasteles como las empanadas o empanadillas ${ }^{37}$. Los frascos de confites, de igual manera, fueron consumidos por las familias francesas más adineradas, como la del hacendado don Santiago Randich; así como las tabletas de leche y las cerezas (estas últimas preferentemente inglesas).

35. Haciendas como Fraternidad compartía la producción de café con la de cacao y esto permitía disponer de la variedad del fruto.

36. En las testamentarias de algunos hacendados como don Gustavo Ruche Bacelais, don José Maroto y don Santiago Randich aparecen listas de alimentos que permitieron recrear, según la utilidad de estos, de qué manera eran consumidos.

37. En la lista de productos alimenticios encontrados en la hacienda de don José Maroto tras su muerte aparecía la empanadilla como un alimento ya cocinado. 
Un hecho importante fue dedicar parte de las tierras pertenecientes a sus haciendas a la ganadería y a la crianza de otros animales, permitiendo suministrarse en gran medida los alimentos básicos para cada comida. Haciendas como la de las familias Maroto y Savine disponían de gallineros, palomares y pateras, incluyendo la crianza de puercos y reses en grandes cantidades ${ }^{38}$. Las carnes de vaca y cerdo formaron parte de la diversidad de los platos fuertes en conjunto, como la nombrada carne del norte (carne para esclavos, según el historiador Ismael Sarmiento), común en las comidas de los hacendados franceses como don Carlos Debrosse; al igual que la carne de las aves, esta era aprovechada como un sustento más en la alimentación.

Los alimentos importados o vendidos en la ciudad, como la salchicha enlatada, el salchichón, el bacala ${ }^{39}$ y las latas de champińón ${ }^{40}$, no faltaron en las listas de compras confeccionadas por las damas encargadas de que los buenos hábitos alimenticios que los distinguían como familias elitistas no se perdieran ${ }^{41}$. Otros acompańantes para la comida fueron el arroz y el frijol, este último cultivado en algunas haciendas, tanto para el consumo interno como para la venta del fruto ${ }^{42}$. Las pastas también

38. La familia Savine disponía de 57 mulos de carga, 79 reses de todas edades, 110 puercos, 1 burro hechor francés y 1 burro hechor criollo.

39. Este alimento no solo fue consumido por los dueños del cafetal. Partiendo de las investigaciones de Ismael Sarmiento, el bacalao hasta la segunda mitad del siglo XIX constituía uno de los renglones básicos de la alimentación esclava. Para más información consultar Alimentación y relaciones sociales en la Cuba Colonial de este historiador.

40. El champiñón común o champiñón de Paris tiene un sabor neutro y delicado, con un aroma ligeramente nogado en los ejemplares más maduros. Es popular en gastronomía, rico en fibra alimentaria.

41. Esta aclaración forma parte del estudio que hizo la Docta en Ciencias Aida Liliana Tejeda Morales en su libro El signo francés, en Santiago de Cuba, p. 221.

42. En la testamentaria de don Carlos Debrosse, dueño del cafetal "Armonía", aparece un cheque del 23 de julio de 1859 con estuvieron dentro de la preferencia alimenticia; los fideos se convertían en la base de algunos platos como los espaguetis.

Las bebidas fueron un componente significativo dentro del panorama refinado del hacendado francés, un símbolo de buen gusto y poder. Los almacenes conservaban garrafones de vino y cajas de cerveza en botellas para celebraciones y uso cotidiano. Las bebidas más elegantes se reservaban para los brindis, las festividades y las reuniones que disponían de la presencia de familias con un alto estatus social dentro de la comunidad francesa establecida en el partido o las llegadas de la ciudad.

Las cenas generalmente se acompañaban de finos vinos, familias como los Bacelais preferían los provenientes de $\operatorname{Medoc}^{43}$, una región de Francia conocida por ser productora, en especial, de vino tinto. Para ocasiones especiales se compartía con uno de los tragos más delicados, el Brandy, obtenido a través de la destilación del vino y se guardaba en grandes cantidades, incluso en barriles. El cońac, por otra parte, fue otra de las bebidas consumidas por los galos; el hacendado Santiago Randich disponía de cajas de coñac en su hacienda Plasencia.

A pesar de lo antes planteado, hacendados como don José Alberto Dufourg preferían típicas bebidas refrescantes producidas en países como España. Tal es el caso de la sangría, normalmente consistente en vino tinto, frutas picadas, un endulzante y algún licor. Esta bebida de mesa comúnmente se presenta en jarras transparentes para dejar ver las frutas con las que la sangría se encentra aderezada, por lo que puede suponerse que se utilizaban las llamadas damajuanas para la preparación y el consumo de dicha bebida.

la venta de 8 sacos de frijoles provenientes de dicha hacienda.

43. Ubicada en el departamento de la Gironda, en la orilla izquierda del estuario de la Gironda, al norte de Burdeos. La región debe su éxito económico principalmente a su producción de vino tinto, tiene cerca de 1500 viñedos. 
Las bebidas dulces, como los licores en su variedad y el ron, también fueron compartidos en familias franco domingoises. No aparecen datos en los archivos que hicieran alusión en las haciendas de domingueños a la presencia de vinos o tragos a la altura de la calidad de los bebidos por los franceses. Los ambientes festivos para estas familias no se correspondía con la de los galos, al menos que llegaran a obtener un caudal como los Casamayor o Lescaille, familias también presentes en el partido.

Para los días de celebración, según muestra la doctora María Elena Orozco, el espacio destinado a la vivienda-almacén de estas plantaciones cafetaleras constituyó especies de "salones”: “(...) En ellos se celebraron diferentes actividades sociales y se hicieron los "zaraos" o "arribotas", como algunos catalanes llamaron despectivamente (...) a las fiestas que se celebraban en la casa de los franceses y a las que concurría el patriciado santiaguero (Orozco, 2015)".

En los días festivos o las reuniones importantes acompañaba a los finos tragos un buen tabaco. En las haciendas de los franceses Santiago Randich y Miguel Ruche Bacelais llegaron a disponer de más de una caja para uso cotidiano y quinientos tabacos de reserva. Lucían su peculio a través de sus elegantes bebidas y cigarrillos, vestidos con los últimos acontecimientos de la moda francesa del siglo XIX.

En el caso de la moda, el estilo francés del siglo XIX perduró incluso en las zonas montañosas. Los mismos referentes parisinos reflejados en la ciudad se mostraban en el campo. Si bien existen documentos que alegan la presencia de establecimientos dedicados a la sastrería y a la venta de ropas a la francesa en la ciudad, así como artículos de periódicos anunciando las características de dicho estilo, las testamentarias de las familias francesas que se desenvolvían en la zona rural son testimonio de las vestimentas, prendas, zapatos y accesorios que estos disponían.
El hacendado como representante de su familia y del poderío de esta fue la figura que más se caracterizó en los testamentos ${ }^{44}$. La indumentaria de estos se convertía en reflejo del nivel económico que poseían y vivir en el campo los posicionaba en el ojo crítico de la sociedad ilustrada que permanecía en la ciudad. No obstante, el clima fue un factor que incidió en la transformación de la moda francesa que se establece.

En un país donde las temperaturas son elevadas gran parte del año, se vestían con casacas, chaquetas o levitas negras, pantalones largos, generalmente blancos, chaleco del mismo color, corbata y sombreros de copa negros. En Santiago de Cuba, donde el clima es más cálido, los caballeros sin dejar de ser elegantes hicieron ciertas transformaciones en su vestimenta y prefirieron usar con frecuencia el traje de dril blanco y el elegante sombrero de indiana jipijapa (Marrero, 1977, pp. 213-215) ${ }^{45}$.

En el partido Ramón de las Yaguas, según las referencias de los archivos, los hacendados franco domingoises vestían con camisas de algodón o seda y pantalones de dril blanco, los más adinerados se mostraban con pantalones del ara de oro. Presentaban levitas, casacas y chalecos de paño negro a pesar de las altas temperaturas, otros eran de seda, negros o piqué. Las corbatas en reiteradas ocasiones también eran de seda negra con sus alfileres de oro.

\footnotetext{
44. La mayoría de los testamentos pertenecientes a familias del partido Ramón de las Yaguas son de hacendados, o sea, de hombres, muy pocos casos los hay de mujeres (las pertenencias de las hacendadas aparecen cuando el testamento es compartido); por tanto, los atuendos que aparecen le corresponden en gran parte a los hacendados.

45. Para más información sobre la influencia de la moda francesa en Santiago de Cuba durante el siglo XIX, revisar la tesis de diploma de las licenciadas en Historia del Arte Tania Basterrechea Ricardo y Xochill Arrigas Pereiro: Marcos de vida: influencia de la moda francesa en Santiago de Cuba.
} 
Estos atuendos no solo fueron privilegios para los hacendados galos, pues francos como don José Maroto también lo exhibían. "Una de las prendas masculinas de moda en la década de 1850 fue el paletó (...) era un gabán de paño grueso, largo y entallado, pero sin faldas como el levitón (Morales, 2015, p. 194)". Esta prenda tuvo gran aceptación para los hacendados del partido, como fue el caso del francés don José Alberto Dufourt ${ }^{46}$, quien confió la calidad de sus ropas y la autenticidad de los modelos galos de la época a la sastrería Arnoult ${ }^{47}$ (un local establecido en la calle Enramadas), muy solicitados por las familias francesas de la urbe.

Figura 6. Recibo de la entrega de artículos de una sastrería

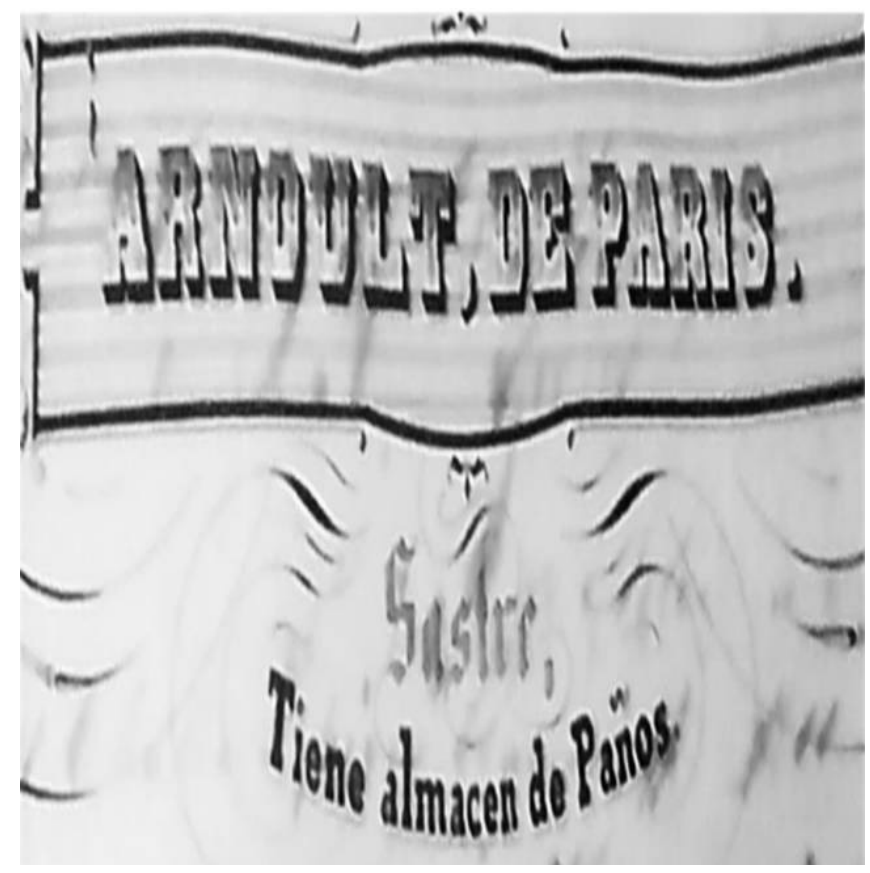

Fuente: Archivo Provincial de Santiago de Cuba, adjunto a la Testamentaria del hacendado don José Alberto Dufourt.

46. Hijo legítimo de don Juan y doña Faustina Girusta, naturales en Arthesen Francia. Poseía bienes en la sociedad de Wright Brooks y Compañía.

47. En la testamentaria de Dufourt aparece una tarjeta que muestra las ropas hechas en esta sastrería coincidiendo con las mismas características y nombre de la sastrería que la investigadora Aida Liliana Morales hace alusión en su libro El signo francés, p. 87.
Para acompañar los trajes revelaban accesorios lujosos que lo distinguían como una personalidad de buenos negocios: reloj de bolsillo con su cadena de oro y plata, así como sortijas y cadenas de oro. Otros hacendados franceses como don Gustavo Ruche Bacelais y criollos como don Juan Mena Garibaldo (capitán del partido para el año 1856) ${ }^{48}$ también mostraban dichas prendas.

El sombrero se convirtió en un accesorio importante para los caballeros de la época. Aunque investigaciones sobre la moda santiaguera en el siglo XIX posicionan al sombrero de indiana de jipijapa como el más común en la sociedad del momento por ajustarse a las características del clima tropical (Morales, 2015, p. 208), los testamentos de los hacendados del partido revelan la presencia de sombrero de pajas, también conocido como canotier. Este accesorio de copa recta, con la parte superior plana y ala corta y rígida, generalmente adornado con una cinta de color o negra, en la ciudad fue reservado para situaciones de etiqueta, mientras (Basterrechea, 2007, p. 20) en la zona rural tuvo un uso más cotidiano. El hacendado Alberto Dufourt disponía de cuatro sombreros de paja; sin embargo, don Juan Pedro Ivonet contaba con un solo ejemplar.

Por otra parte, los bastones estuvieron presentes de igual manera en los hacendados del partido. Eran sinónimo de distinción entre los hombres que lo portaban generalmente en la mano izquierda, el lado donde los aristócratas llevaban las espadas antes de la Revolución Francesa. Algunos franceses

48. Natural de la ciudad de la Habana. Hijo legítimo de don Manuel José de Mena y Augusto (tesorero general del ejército, jubilado) y de dońa Isabel Ignacia Garibaldo. Este contrajo matrimonio con doña Higima de Anaya, juntos se encontraban al frente del cafetal Unión, en el Partido las Yaguas. Poseían además un colgadizo en la calle de Santo Tomás \# 42 con un carruaje para pareja. APSC, Juzgado de Primera Instancia, Testamentos, Leg, 696, exp. 2, 1859. 
llegaron a tener en sus haciendas alrededor de cinco bastones $^{49}$.

En el caso del calzado, los más comunes eran las botas y los botines finos; algunos testamentos también hacían referencia a botincitos. Este tipo de zapatos lo mismo los calzaban los hombres que las mujeres. Las damas y señoritas establecidas en el partido, como las hermanas Rosa Julia Sidonia y Cecilia Ruche Bacelais, preferían mostrar botines de fina marca como Napoleón y pendientes de nácar ${ }^{50}$.

Las damas no frecuentaban la ciudad como los caballeros, solo en ocasiones especiales o festivas. Las presentaciones de obras de teatro fue uno de los escenarios más acorde para que las señoritas del campo mostraran sus trajes y accesorios, dejando ver el poder económico de su familia ${ }^{51}$. Exhibían sus sombrillas, pañuelos de seda y algodón de finas marcas como Batista o Tafetán, guantes, abanicos, broches y peinetas. Su presencia hacía evidente que la distancia entre ambos espacios vivenciales no fuese un factor que incidiera en la imagen de las familias establecidas en la zona rural $y$, por ende, en el partido.

Los ideales culturales desarrollados en el partido Ramón de las Yaguas mantenían los referentes ilustrados de las familias francesas establecidas en la ciudad. Las costumbres y los comportamientos reflejados en las haciendas cafetaleras respondían a tipologías de la zona rural, pero conservando un estilo de vida a la francesa. El decorado y amueblamiento, el buen vestir y comer, así como

49. El hacendado don José Alberto Dufourg poseía cinco bastones. Este dato fue encontrado en las cuentas establecidas en su testamento.

50. Estos datos aparecen en el intestado de don Gustavo R. Bacelais.

51. 115 Las sobrinas de dońa Dinet Duport, establecidas en la hacienda Hermitaño y Plasencia, vestían de lujo para asistir a la presentación de la obra Pata de Cabra, exhibida en el teatro Coliseo. APSC, Juzgado de Primera Instancia, Testamentos, Leg. 603, Exp. 1, 1840. la satisfacción de brindar con elegantes tragos, aludían a la presencia del signo francés en el partido.

\section{Conclusiones}

Los aportes culturales franceses desarrollados en el partido Ramón de las Yaguas mantenían los referentes ilustrados de las familias francesas establecidas en la ciudad. El estilo parisino estaba presente, aun y cuando emergían nuevas modalidades condicionadas por el clima tropical y las circunstancias propias de la llamada cultura del café.

Los comportamientos, las costumbres, y la dinámica habitacional presente en las haciendas cafetaleras respondían a las tipologías de la zona rural, sin embargo, en todo momento conservando un estilo de vida a la francesa. Las moradas atesoraban objetos de lujo, traídos desde Francia o confeccionados por ebanistas franceses emigrados que mantenían la calidad del estilo. La visión galante de la época se concentraba en la exhibición de alhajas y finas vajillas, presumiendo del nivel económico que poseían. Consumían alimentos importados y obtenidos de las propias crianzas de la hacienda, mientras las bebidas se convirtieron en símbolo de buen gusto y poder. Licenciado en Historia del Arte. Vivir en el campo no fue un acontecimiento desmeritado. Estas familias eran reconocidas por sus ingresos económicos en la dinámica del comercio interior y exterior a la isla de Cuba, a través de la caficultura.

\section{Bibliografía}

Basterrechea Ricardo, T. (2007). Marcos de vida, influencias de la moda francesa en Santiago de Cuba. Santiago de Cuba: Tesis de Diploma para optar por Licenciado en Historia del Arte.

Contreras Soto, R. (2008). Análisis Critico de la Cultura. Prácticas culturales, en Contribuciones a 
las Ciencias Sociales, enero 2008. Recuperado de www.eumed.net/rev/cccss/0712/rcs4.htm

Godínez, L. (2013). Del paisaje natural al paisaje cultural: concepción de Ti Arriba y la presencia francesa. Santiago de Cuba: Licenciada en Historia del Arte.

López Segrera, Y. (2010). Del paradigma tecnológico al paisaje arqueológico: presencia francesa y cultura del café en el sudeste cubano en la primera mitad del siglo XIX. Santiago de Cuba: Tesis presentada para optar por el grado científico de Doctora en Ciencias sobre Arte.

Morales Tejeda, A. L. (2015). El signo francés en Santiago de Cuba. Santiago de Cuba: Oriente.

Orozco Melgar, M. E. (2008). Génesis de una ciudad del Caribe: Santiago de Cuba en el umbral de la modernidad. Santiago de Cuba: Alqueza.

Orozco Melgar, M. E. (2015). Santiago la patria soñada: del imaginario a la realidad. Santiago de Cuba. (Presentación de una conferencia).

Padrón, C. (1994). Índice de franceses en el suroriente de Cuba. Del Caribe, No. 23.

Pérez de la Riva, F. (1994). El café, historia de su cultivo y explotación en Cuba. La Habana: Jesús Montero.

Pezuela, J. d. (1866). Diccionario Geográfico, Estadístico, Histórico de la isla de Cuba. Tomo IV. Madrid: Imprenta del Banco Industrial y Mercantil.

Portuondo Zúñiga, O. (2014). Francia y Haití en la cultura cubana. La Habana: José Martí.

Rizo, L. (2003). La arquitectura cafetalera en Cuba. Siglo XIX. Santiago de Cuba: Tesis de maestría.

Sarmiento, I. (2003). Alimentación y relaciones sociales en la Cuba Colonial. Anales del Museo de América II (11), pp.197-226.

\section{Fuentes primarias o archivos}

AHPSC. Juzgado de Primera Instancia. Testamentos. Legajo 601, expediente 3, año 1840. Intestado de Don Miguel Enrique Bacelais.

AHPSC. Juzgado de Primera Instancia. Testamentos. Legajo 603, expediente 1, año 1840. Testamentaria de Doña Luisa Dinet.

AHPSC. Juzgado de Primera Instancia. Testamentos. Legajo 616, expediente 1, año 1842. Primera Pieza de los autos testamentarios de Don Pedro Leglis Labal.

AHPSC. Juzgado de Primera Instancia. Testamentos. Legajo 642, expediente 1, año 1846. Autos testamentarios de Don Juan Pedro Ibonet.

AHPSC. Juzgado de Primera Instancia. Testamentos. Legajo 645, expediente 6, ańo 1847. Diligencia promovida por Don Miguel Teodoro Morasin, sobre calificación del poder que, desde la ciudad de París, Corte del Reyno de Francia, le ha conferido a Dońa Luisa Sofía Eugenia Girard (...)

AHPSC. Juzgado de Primera Instancia. Testamentos. Legajo 658, expediente 4, año 1849. Segunda pieza de los autos testamentarios de D. Clemente Praud.

AHPSC. Juzgado de Primera Instancia. Testamentos. Legajo 688, expediente 1, año 1856. Testamentaria de Don José Maroto.

AHPSC. Juzgado de Primera Instancia. Testamentos. Legajo 691, expediente 1, año 1857. Testamentaria del doctor Ángel Alberto Savine promovida por su albacea y legatorio D. Carlos Coste.

AHPSC. Juzgado de Primera Instancia. Testamentos. Legajo 696, expediente 2, año 1859. Testamentaria de Don Juan de Mena Garibaldi e Intestado de Dońa Higimia de Anaya su consorte.

AHPSC. Anotaduría Hipotecaria. Fincas Rústicas. Libro 36. Año 1843, pág. 112. Mitad que le 
pertenece a Don Eugene de Ribeaux en las haciendas de café situada en el partido del Azomante, tituladas: Fraternidad y la otra Candelaria, en el partido del mismo nombre.

AHPSC. Anotaduría Hipotecaria. Fincas Rústicas. Libro 37. Año 1848. Mitad que le pertenece a Don Federico Lecaille en la hacienda de café Parábola, situada en el partido del Ramón de las Yaguas.

AHPSC. Anotaduría Hipotecaria. Fincas Rústicas. Libro 38. Año 1852- 1857. Cafetal titulado
Josefina, situado en el partido del Ramón de Don Juan Bautista Duverger.

AHPSC. Anotaduría Hipotecaria. Fincas Rústicas. Libro 30. Año 1870. Mitad del cafetal cacotal Fraternidad con su anexo Santa Paulina, en el cuartón central del partido de las Yaguas: Cafetal cacotal La Emilia en los mismos Cuartón y Partido: Casco de cafetal Nueva Cecilia, en el propio partido cuartón del Ramón.

\section{Datos de filiación}

Claudia López Moreno. Licenciada en Historia del Arte en la Universidad de Oriente. Santiago de Cuba. Actualmente se desempeńa como profesora de la Facultad de Humanidades de esta alta casa de estudios. Su investigación se ha concentrado en el estudio del patrimonio tangible e intangible relacionado con la presencia francesa en el oriente cubano. Correo electrónico: claudia.lopez@uo.edu.cu 